Article

\title{
Neutron Activation Analysis in Urban Geochemistry: Impact of Traffic Intensification after Opening the Blanka Tunnel Complex in Prague
}

\author{
Jiří Mizera ${ }^{1,2, * \mathbb{D}}$, Martina Havelcová ${ }^{2} \mathbb{D}$, Vladimír Machovič ${ }^{2,3}$, Lenka Borecká ${ }^{2}$ and Dominik Vöröš $^{2} \mathbb{D}$ \\ 1 Nuclear Physics Institute, Czech Academy of Sciences, Hlavní 130, 25068 Husinec-Řež, Czech Republic \\ 2 Institute of Rock Structure and Mechanics, Czech Academy of Sciences, V Holešovičkách 41, \\ 18209 Praha 8, Czech Republic; havelcova@irsm.cas.cz (M.H.); vladimir.machovic@vscht.cz (V.M.); \\ borecka@irsm.cas.cz (L.B.); voros@irsm.cas.cz (D.V.) \\ 3 Central Laboratories, University of Chemistry and Technology Prague, Technická 5, \\ 16628 Praha 6, Czech Republic \\ * Correspondence: mizera@ujf.cas.cz
}

check for updates

Citation: Mizera, J.; Havelcová, M.; Machovič, V.; Borecká, L.; Vöröš, D. Neutron Activation Analysis in Urban Geochemistry: Impact of Traffic Intensification after Opening the Blanka Tunnel Complex in Prague. Minerals 2022, 12, 281. https://doi.org/10.3390/ $\min 12030281$

Academic Editor: Fernando Rocha

Received: 24 January 2022

Accepted: 22 February 2022

Published: 24 February 2022

Publisher's Note: MDPI stays neutral with regard to jurisdictional claims in published maps and institutional affiliations.

Copyright: (c) 2022 by the authors Licensee MDPI, Basel, Switzerland. This article is an open access article distributed under the terms and conditions of the Creative Commons Attribution (CC BY) license (https:/ / creativecommons.org/licenses/by/ $4.0 /)$.

\begin{abstract}
Opening of the Blanka Tunnel Complex (BTC) in Prague, Czech Republic, the longest city tunnel in Europe, significantly increased traffic on a connected main road, the V Holešovičkách street (VHS). To study environmental changes in VHS connected with BTC opening, sampling of road dust and airborne particulate matter in the VHS vicinity started 3 years before BTC opening and continued until BTC pilot operation. The enrichment factors calculated for the collected samples from elemental compositions determined by instrumental neutron activation analysis (INAA) have shown significant enrichment for $\mathrm{Se}, \mathrm{Sb}, \mathrm{Hg}, \mathrm{Br}, \mathrm{Mo}, \mathrm{Zn}, \mathrm{As}, \mathrm{W}, \mathrm{Cr}, \mathrm{Ba}$, and $\mathrm{Fe}$, but not their increase after starting BTC operation. The Principal Component Analysis allowed distinguishing between detrital and anthropogenic, probably traffic related, origin of the elements determined in samples. The study demonstrated a potential of INAA for multielement trace analysis of minute samples (28 elements determined in samples down to $20 \mu \mathrm{g}$, with detection limits down to sub-ng level) and its application in urban geochemistry studies.
\end{abstract}

Keywords: Blanka Tunnel Complex; heavy traffic; road dust; airborne particulate matter; INAA

\section{Introduction}

The Blanka Tunnel Complex (BTC), a part of the Prague City Circle Road (an inner ring road), is $5.5 \mathrm{~km}$ long, the longest road tunnel in the Czech Republic and the longest city tunnel in Europe. Designed to relieve the historic center of Prague from heavy traffic, it connects the area west of Prague Castle (Hradčany district) with the Troja district in the northeast (Figure 1). The construction of BTC started in 2007. Initially due to open in 2011, BTC was officially opened to the public in September 2015 but remained in a pilot operation until the final inspection and approval in October 2019. In January 2021, the Municipal Court of Prague sustained a petition of residents and cancelled the approval for a larger part of the complex (a section between Špejchar and Pelc-Tyrolka, adjacent to the area of this study) [1].

Model calculations [2] have shown that starting BTC operation will significantly increase traffic on a connected main road, the V Holešovičkách street (VHS), which passes through a compact populated area with a length of $1.6 \mathrm{~km}$ (Figure 1). Typical daily (workweek) traffic in VHS increased from about $70 \mathrm{k}$ to $80-90 \mathrm{k}$ vehicles after BTC opening (Figures 2 and 3). The 10-20 k increase is comparable with a difference between workweek and weekend traffic in VHS (see the oscillations in Figure 3). The expected negative environmental impact of BTC operation on VHS and the surrounding residential area, particularly increased noise level and emissions, has raised concern and complaints of local 
residents. On the BTC information web portal [3], results of an air quality survey $\left(\mathrm{PM}_{10}\right.$ and $\mathrm{PM}_{2.5}, \mathrm{NO}_{2}$, benzo[a]pyren) in monitoring sites approved by the Environmental Protection Department of the Prague City Hall are available. The survey was carried out in four 28-day stages starting just before BTC opening and covering both heating and non-heating seasons. Excerpts from the available data for traffic volume and for $\mathrm{NO}_{2}$ and $\mathrm{PM}_{10}$ measured in VHS are presented in Figure 3 (for location of the monitoring site see tag 2 on the maps in Figure 1). The data show clearly that air quality in VHS suffered from heavy traffic already before BTC opening and during its pilot operation, and that air quality standards have been exceeded repeatedly, namely in smog situations and unfavorable meteorological conditions with poor dispersion (e.g., August 2015 and February 2016, respectively). The air quality standards according to the Czech Air Protection Act (No. 201/2012 Coll., on the air protection, Suppl. No. 1) are identical with the European standards given by the directive 2008/50/EC [4], i.e., $\mathrm{NO}_{2}$ annual average below $40 \mu \mathrm{g} \mathrm{m}^{-3}$ and each year 18 permitted exceedances of a $1 \mathrm{~h}$ average $200 \mu \mathrm{g} \mathrm{m}^{-3}$, and PM10 annual average below $40 \mu \mathrm{g} \mathrm{m}^{-3}$ and each year 35 permitted exceedances of a $24 \mathrm{~h}$ average $50 \mu \mathrm{g} \mathrm{m} \mathrm{m}^{-3}$. On the other hand, the trends observed for the air pollutants $\mathrm{NO}_{2}$ and $\mathrm{PM}_{10}$ are not unambiguously correlated with the trend for traffic volume which significantly increased after BTC opening. According to a statement from the BTC information web portal, emissions have been decreased thanks to improving traffic smoothness and passability of the road, which together with other organizational and technical measures contribute also to reduction in traffic noise level in the VHS surrounds.

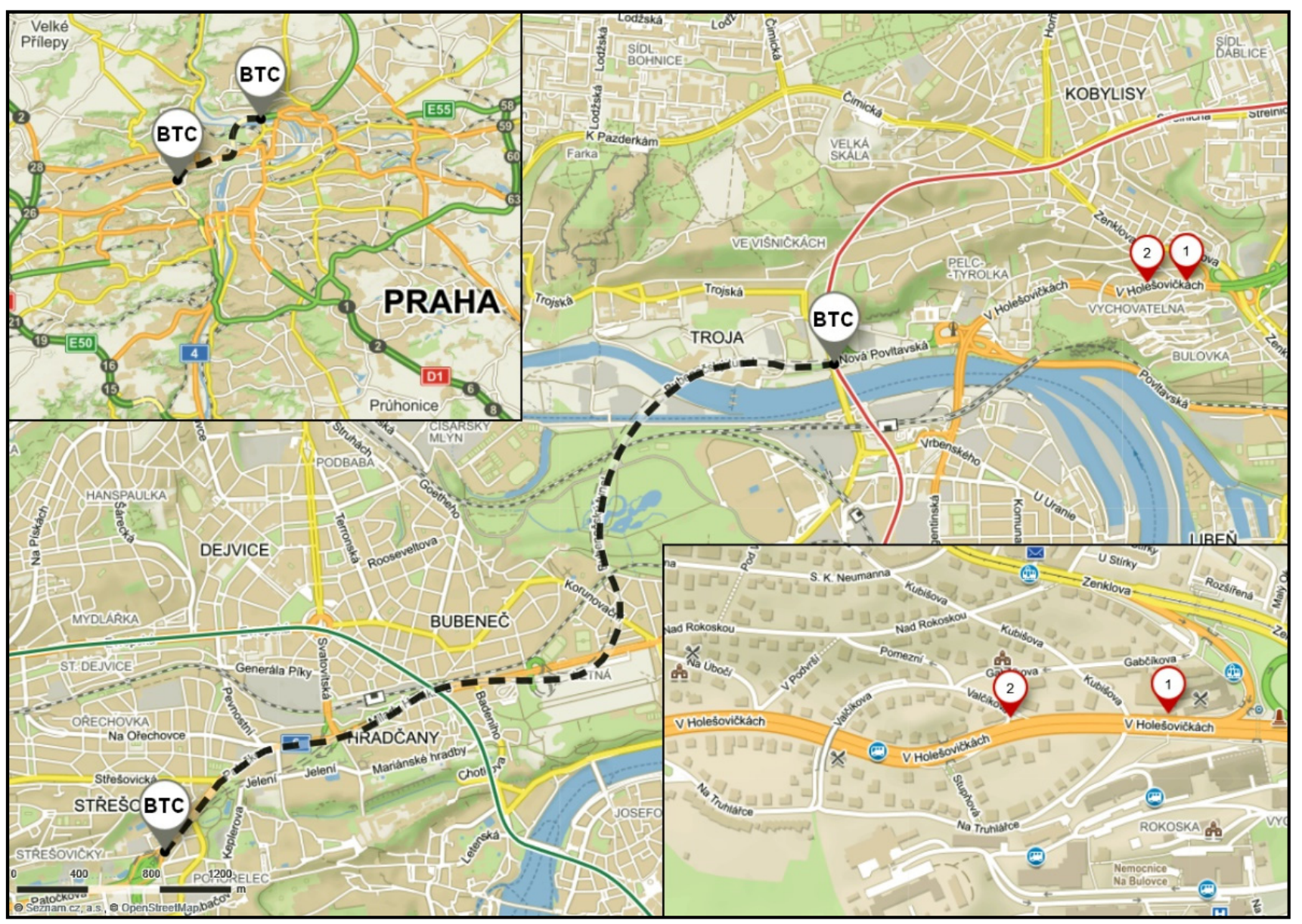

Figure 1. Map of the Blanka Tunnel Complex (BTC), its location in a map of Prague, and details of the V Holešovičkách street with the locations of the dust sampling sites (tag 1) and an air quality monitoring station (tag 2). 


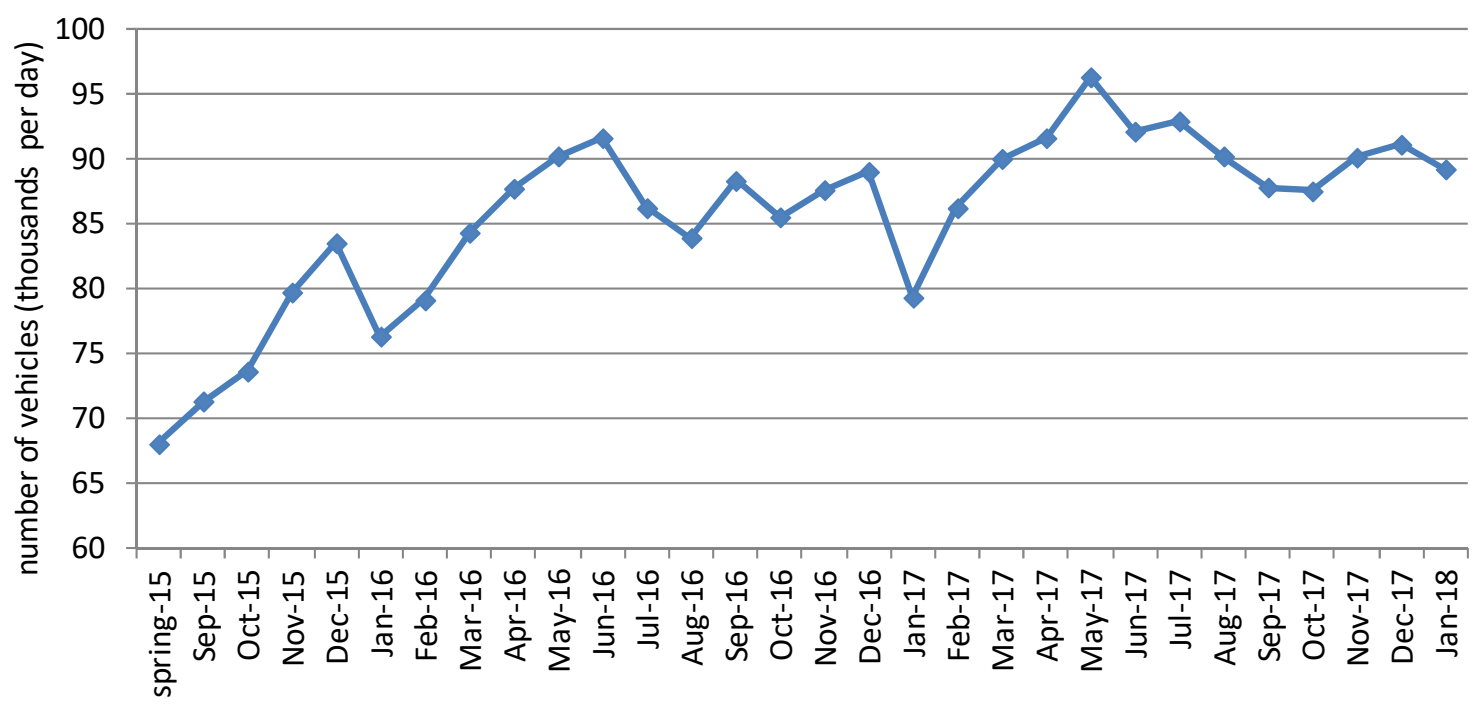

Figure 2. Development of the daily traffic in the V Holešovičkách street in connection with operation of the Blanka Tunnel Complex that started in September 2015 (averaged daily numbers of vehicles). Data taken from [5].
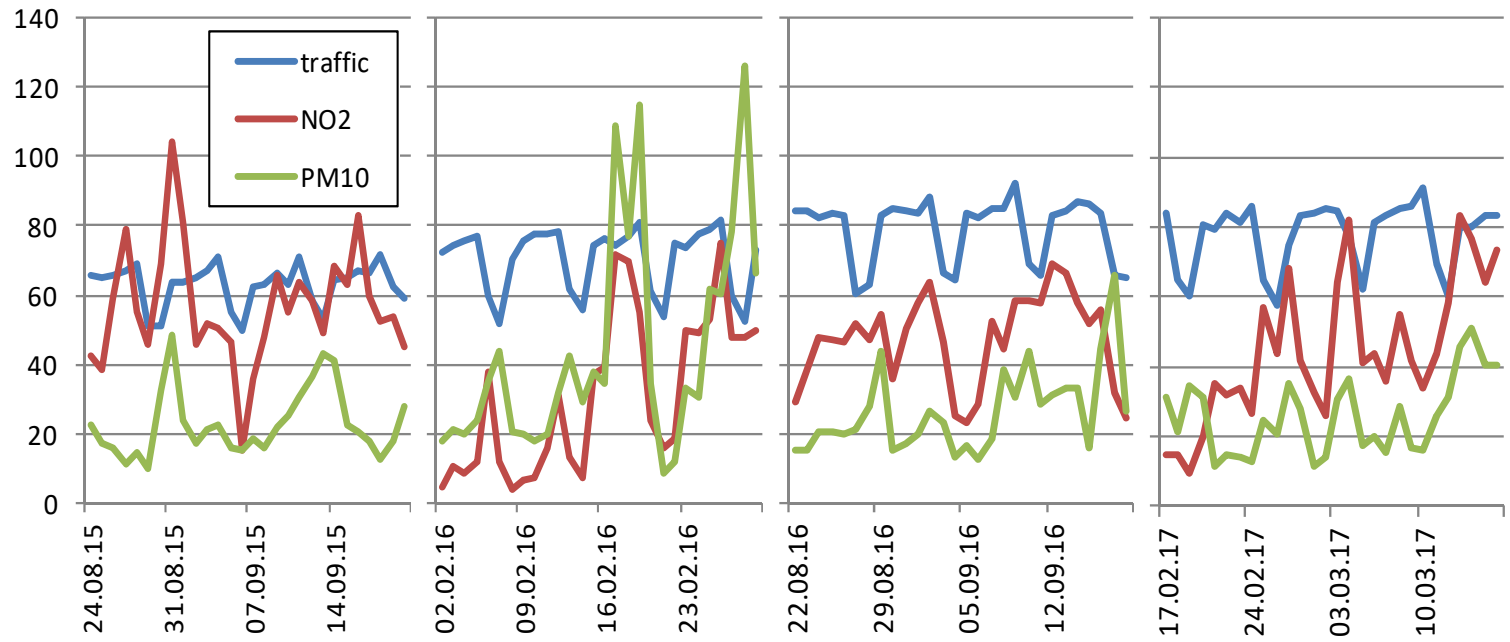

Figure 3. Results of the 4-stage air quality survey in the V Holešovičkách street (traffic: daily thousands of vehicles; NO2, PM10: 1 and 24 h averages of $\mathrm{NO}_{2}$ and $\mathrm{PM}_{10}$ concentrations, respectively, $\left.\mu \mathrm{g} \mathrm{m}^{-3}\right)$. Data taken from [3].

Besides noise level and the standard air quality parameters $\left(\mathrm{PM}_{10}\right.$ and $\mathrm{PM}_{2.5}, \mathrm{NO}_{2}$, benzo[a]pyren), a suitable parameter for assessing the environmental impact of heavy traffic could be elemental (or generally chemical) composition of road dust (RD) and airborne particulate matter (APM). Although epidemiological and toxicological studies indicate a number of health outcomes from transport-related air pollution, little information is available on the chemical composition of APM from exhaust emissions, and the European air-quality standard for APM has no standard for its chemical composition [6].

Location of the Institute of Rock Structure and Mechanics, Czech Academy of Sciences (IRSM) in VHS, next to a multilevel crossing of the connected Liberecká street with the Zenklova street (see tag 1 on the maps in Figure 1) has been considered suitable for monitoring the expected environmental changes related to changes in traffic volume after opening BTC. Moreover, IRSM is located just several hundred meters from the air quality monitoring station (tag 2 in Figure 1). Already in 2012, during the prolonged construction of BTC, sampling of RD from VHS and its study was started at IRSM, continued by sampling of the APM. The study included characterization of elemental composition of the collected 
samples by means of instrumental neutron activation analysis (INAA), and additional compositional characterization and identification of particles of APM by SEM/EDX (not included in the present study). Three sets of samples collected in the street vicinity were acquired: a set collected long before BTC opening from December 2012 to September 2013, a set collected shortly before BTC opening in June and July 2014, and a set collected immediately before BTC opening and during its pilot operation from February 2015 to April 2016.

The present work aimed at presenting elemental compositions of RD and APM collected in the vicinity of VHS as a heavy traffic area affected by operation of BTC. Correlations between elements and their enrichment factors were applied to assign their potential association with traffic. Comparisons between samples collected before and after BTC opening, with respect to seasonal and spatial effects, were used to observe the relationship of compositional variation in the studied dust samples to traffic intensification. All elemental data were acquired using the instrumental neutron activation analysis (INAA), whose potential for geochemical analysis has been demonstrated in other papers of the current Minerals Special Issue. The research presented in our work is an example of INAA application in so called "urban geochemistry", a field combining geochemistry with environmental science and ecology. The International Association of GeoChemistry (IAGC) re-established its Urban Geochemistry Working Group in 2014 to develop a broader interest in urban landscapes within the geochemical community. In a special issue of the Applied Geochemistry journal, a series of the urban geochemistry-oriented papers was published in 2017 [7].

\section{Geological Setting of Study Area}

The geological subsurface of the study area (Figure 1: Troja, Kobylisy, Libeň districts) consists of three principal tectono-stratigraphic units: the metamorphosed Cadomian basement, which is covered by folded Lower Paleozoic deposits of the Prague (Barrandian) Basin corresponding to the Hercynian (Variscan) floor, and the youngest Cretaceous to Quaternary platform cover deposits. The oldest Neoproterozoic to early Cambrian marine siliciclastic deposits (greywackes, siltstones, shales) locally intercalated with submarine paleo-basalts and tectonically stacked into an accretionary complex, that experienced lowgrade regional metamorphism and deformations during the Cadomian orogeny. Overlying lower Palaeozoic (late Cambrian to middle Devonian) deposits of the Prague Basin are separated from the Cadomian basement unit with a clear angular unconformity. In the study area, Palaeozoic deposits are represented mainly by Ordovician marine siliciclastic turbidites and black shales that accumulated in a deep water setting on an ancient passive continental margin. Unmetamorphosed, continental Upper Cretaceous sandstones and marls and variable Quaternary sediments (e.g., fluvial sands, conglomerates, loess) representing a flat-lying platform cover both the Cadomian basement and Lower Palaeozoic rocks over much of the study area, except for the deeply incised Vltava River valley where older units exhumed by river erosion are accessible [8-10].

\section{Materials and Methods}

\subsection{Sampling of Road Dust and Airborne Particulate Matter}

The present study deals with two basic types of samples. At the earliest sampling stage (12/2012-09/2013), RD samples were collected by brushing from the surface of a ledge of foundation wall at a $5 \mathrm{~m}$ distance from the VHS edge and at a $0.5 \mathrm{~m}$ height (see Figure 4A). This primitive sampling procedure, however, suffered from weather conditions and was not representative of the environmental situation at a larger distance from VHS, in the residential area suffering most from the heavy traffic. That is why, in the later stages (06-07/14 and 02/15-04/16), sampling changed to collection of APM on filters, and the sampling site was moved further from VHS (50 m, at a $10 \mathrm{~m}$ height), to reflect better the environmental situation in the residential area. A sampling apparatus with Whatman Nuclepore polycarbonate filters with diameter $45 \mathrm{~mm}$ and pore diameter $10 \mu \mathrm{m}$, 
positioned vertically to be protected from rain or snow, was used. Airflow was measured and controlled $(10 \mathrm{~L} / \mathrm{min})$ only at the last sampling stage $(02 / 15-04 / 16)$. The apparatus is shown in Figure 4B-D. Sampling on filters ran in four stages separated with several-month breaks, with a weekly exchange of filters within each stage (continuous sampling from Monday to Friday with a weekend break). Although the sampling procedure likely did not allow to obtain APM with a well-defined and standard size range, the collected APM should correspond best to the coarse particulate matter $\mathrm{PM}_{10-2.5}$ [11].
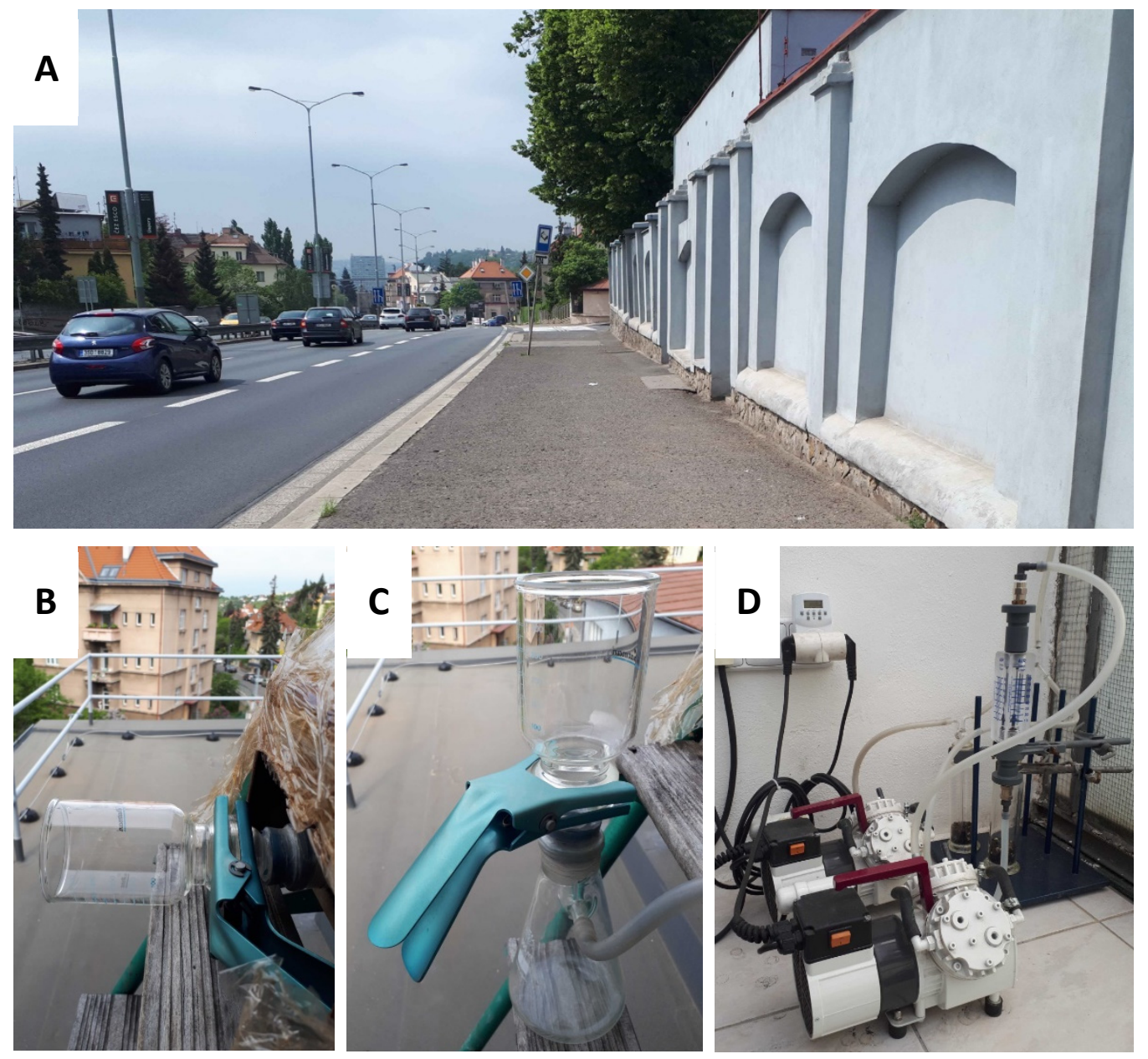

Figure 4. Sampling sites in the vicinity of the V Holešovičkách street. (A) Sampling stage 12/12-09/13, samples swept from wall surface (white ledge) at the street edge. (B,C) A setup used in sampling stages $06-07 / 14$ and $02 / 15-04 / 16$ positioned $50 \mathrm{~m}$ from the street at $10 \mathrm{~m}$ height, samples on filters. (D) Vacuum pump with airflow control (10 L/min).

\subsection{Elemental Characterization by INAA}

Instrumental neutron activation analysis (INAA) was used for determination of the elemental composition of the samples of RD and APM collected in the vicinity of VHS. Samples (including blank described below), calibrators, reference materials and neutron flux monitors were irradiated in the LVR-15 research nuclear reactor of the Research Centre $\breve{R e z ̌}$. These were packed in heat-sealed capsules (diameter $25 \mathrm{~mm}$ ) made of lowblank polyethylene. Filters were folded to a suitable size. The whole set including up to 30 samples, besides the auxiliary material, was packed as a stacked column in an aluminum irradiation can. A standard INAA procedure [12,13] included irradiation for 2 and $4 \mathrm{~h}$ (RD and APM, respectively), and acquisition of gamma spectra of irradiated samples in two counting runs: 4-5 days after irradiation, and 15-20 days after irradiation when shorterlived matrix radionuclides were sufficiently decayed. Gamma spectra were acquired using 
a Canberra coaxial HPGe detector (78\% relative efficiency, FWHM of $1.8 \mathrm{keV}$ at $1332.5 \mathrm{keV}$ line of ${ }^{60} \mathrm{Co}$ ) coupled to a Canberra Genie 2000 gamma-spectrometric system.

The direct comparator calibration method [14] was employed using eight synthetic multi-element calibrators prepared from weighed and dissolved pure elements or their stoichiometric compounds. Elements in the calibrators were grouped and their chemical form chosen to avoid existing spectral or fast neutron interferences [14] and undesirable chemical reactions (precipitation, volatilization) in the solution. Their masses in the mixtures were balanced to account for the activation yield of a given radionuclide. Due to relatively low uranium contents, fission interferences [14] were negligible except for Mo determination via ${ }^{99} \mathrm{Mo}$ where ${ }^{235} \mathrm{U}$ fission produces apparent $1.5 \mu \mathrm{g}$ Mo per $\mu \mathrm{g} \mathrm{U}$ under the applied irradiation conditions in the LVR-15 reactor. Fluctuations of neutron flux were monitored using monitors made of Fe-Co-Mo foil and corrected. Quality control (QC) was provided by analyzing simultaneously with samples two reference materials, NIST RM 8704 Buffalo River Sediment and NIST SRM 2711 Montana Soil, and partially also by checking correlations between lithophile elements such as scandium or rare earth elements. The above information on the analytical procedures and QC is illustrated by Table 1 and Figure 5, which also provide a quick insight into the accuracy, precision, sensitivity, analytical window, linearity, etc., of the method.

Table 1. Radionuclides and photonuclear reactions considered in the application of the short-time irradiation for geochemical analysis.

\begin{tabular}{|c|c|c|c|c|c|}
\hline \multirow{2}{*}{$\begin{array}{l}\text { Analyte Nuclide } \\
\text { (Target Element) }\end{array}$} & \multirow{2}{*}{$\begin{array}{l}\text { Analytical Photopeak } \\
\text { (keV) }[12,15]\end{array}$} & \multirow{2}{*}{$\begin{array}{l}\text { Half-Life } \\
{[12,15]}\end{array}$} & \multirow{2}{*}{$\begin{array}{c}\text { Calibrator No. } \\
\text { (Element Mass in } \mu \mathrm{g})\end{array}$} & \multicolumn{2}{|c|}{$\begin{array}{c}\text { QC (Determined Value to } \\
\text { Reference Value) }\end{array}$} \\
\hline & & & & NIST RM 8704 & NIST SRM 2711 \\
\hline Fe-59 & 1291.6 & $44.5 \mathrm{~d}$ & $1(740)$ & 1.01 & 0.97 \\
\hline $\mathrm{Na}-24$ & 1368.6 & $14.7 \mathrm{~h}$ & $2(21)$ & 1.05 & 0.93 \\
\hline $\mathrm{K}-42$ & 1524.6 & $12.4 \mathrm{~h}$ & $2(250)$ & 0.96 & 0.90 \\
\hline Sc-46 & 1120.5 & $83.8 \mathrm{~d}$ & $3(0.028)$ & 1.14 & 1.02 \\
\hline Cr-51 & 320.1 & $27.7 \mathrm{~d}$ & $3(3.3)$ & 1.10 & 0.95 \\
\hline Co-60 & 1332.5 & $5.27 \mathrm{y}$ & $3(1.0)$ & 0.98 & 0.94 \\
\hline $\mathrm{Zn}-65$ & 1115.5 & $244 \mathrm{~d}$ & $1(99)$ & 0.91 & 0.95 \\
\hline Mo-99 & 140.5 & $65.9 \mathrm{~h}$ & $4(25)$ & 0.61 & not determined \\
\hline $\mathrm{Hg}-203$ & 279.2 & $46.6 \mathrm{~d}$ & $5(6.7)$ & not determined & not determined \\
\hline As-76 & 559.1 & $1.10 \mathrm{~d}$ & $1(1.0)$ & 1.07 & 1.04 \\
\hline Se-75 & 264.7 & $120 \mathrm{~d}$ & $1(10)$ & nd & 0.92 \\
\hline Br-82 & 776.5 & $1.47 \mathrm{~d}$ & $2(2.7)$ & 1.00 & 0.90 \\
\hline $\mathrm{Rb}-86$ & 1076.7 & $18.7 \mathrm{~d}$ & $3(15)$ & 1.04 & not determined \\
\hline Sb-122 & 564.2 & $2.72 \mathrm{~d}$ & $5(1.0)$ & 0.92 & 0.97 \\
\hline Cs-134 & 795.9 & $2.06 \mathrm{y}$ & $3(0.77)$ & 1.08 & 1.01 \\
\hline Ba-131 & 496.3 & $11.8 \mathrm{~d}$ & $2(25)$ & 1.01 & 0.91 \\
\hline La-140 & 1596.5 & $1.68 \mathrm{~d}$ & $6(0.41)$ & 1.00 & 0.92 \\
\hline Ce-141 & 145.4 & $32.5 \mathrm{~d}$ & $7(4.0)$ & 0.87 & 0.92 \\
\hline Nd-147 & 91.1 & $11.0 \mathrm{~d}$ & $7(10)$ & 1.02 & not determined \\
\hline Sm-153 & 103.2 & $1.95 \mathrm{~d}$ & $6(0.13)$ & 0.93 & 0.89 \\
\hline Eu-152 & 1408 & $13.3 \mathrm{y}$ & $6(0.16)$ & 1.07 & 0.96 \\
\hline Tb-160 & 879.4 & $72.3 \mathrm{~d}$ & $6(0.24)$ & 1.12 & not determined \\
\hline $\mathrm{Yb}-175$ & 396.3 & $4.19 \mathrm{~d}$ & $6(0.68)$ & 0.88 & not determined \\
\hline Hf-181 & 482.0 & $42.4 \mathrm{~d}$ & $3(0.19)$ & 1.22 & 1.08 \\
\hline Тa-182 & 1221.4 & $115 \mathrm{~d}$ & $8(0.34)$ & 0.90 & not determined \\
\hline W-187 & 685.8 & $24.0 \mathrm{~h}$ & $4(3.0)$ & not determined & 1.10 \\
\hline Pa-233 (Th) & 312.0 & $27.0 \mathrm{~d}$ & $3(0.29)$ & 1.00 & 0.91 \\
\hline $\mathrm{Np}-239(\mathrm{U})$ & 106.1 & $2.36 \mathrm{~d}$ & $8(2.2)$ & 1.09 & 1.13 \\
\hline
\end{tabular}

The standard INAA procedure under the above conditions (without short-time irradiation mode used for determination of mostly major elements) usually allows the determination of approximately 30 elements. This was possible to achieve with the RD samples collected in a sufficient amount to prepare $\sim 150 \mathrm{mg}$ aliquots for analysis. However, 
collecting the APM on filters yielded samples available for INAA with mass down to $20 \mu \mathrm{g}$ (median $560 \mu \mathrm{g}$ ) with some element masses down to sub-ng level, in which reliable determination of only about 20 elements was possible, as demonstrated also by QC results in Table 1 ( $10 \mathrm{mg}$ aliquots of reference materials were analyzed) and Figure 5. Additionally, relatively high blank contributions from packing material and filters, whose correction by subtraction may be less reliable in the case that content of an element in a sample is comparable with the blank, must be considered. This was a case only for the elements $\mathrm{Br}$, $\mathrm{La}, \mathrm{Ce}$, and $\mathrm{Hg}$.
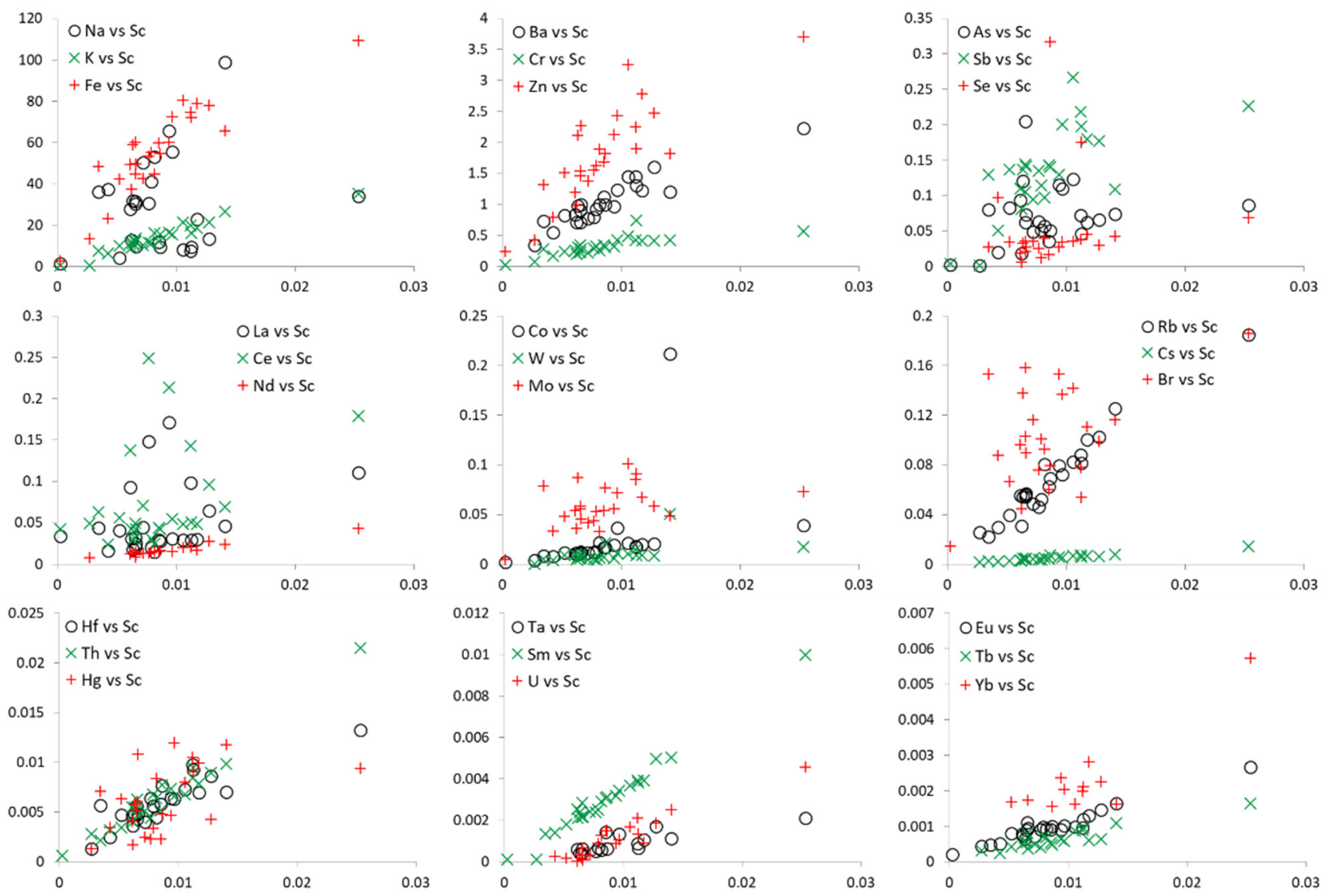

Figure 5. Correlations between individual elements and scandium (y-axis and $x$-axis, respectively; absolute mass in $\mu \mathrm{g}$ ), determined in samples collected in the vicinity of the V Holešovičkách street in relation to operation of the Blanka Tunnel Complex in Prague.

\subsection{Enrichment Factors}

The elemental compositions of the samples of RD and APM from the VHS vicinity determined by INAA were evaluated using the enrichment factors $(E F)$. To assess the extent of anthropogenic contamination, $E F$ for a given element $x$ is calculated as a ratio of its normalized (to a reference element) concentrations in sample and in the uncontaminated environment such as local soil ( $c_{x}$ and $c_{r e f}$, respectively). If a sample representing the local uncontaminated environment is not available, it can be substituted by, e.g., composition of the upper continental crust (UCC). This was the case in this study, regarding the abovedescribed geological setting of the study area with prevalence of typical crustal sedimentary deposits (shale, loess). The UCC average composition was taken from [16]. Scandium, which rarely enters the atmospheric aerosols from anthropogenic sources [17], was used as the reference element.

$$
E F=\frac{\left(c_{x} / c_{r e f}\right)_{\text {sample }}}{\left(c_{x} / c_{r e f}\right)_{U C C}}
$$


The EF evaluation does not require knowledge of a sample mass. This was a great advantage in the case of sampling on filters, where sample mass was negligible compared to mass of a blank filter and, moreover, the filter mass was changing during the sampling period due to wetting/drying. Thus, sample mass could only be estimated based on, e.g., scandium content relative to its UCC content.

\section{Results and Discussion}

\subsection{Analysis of Averaged Enrichment Factors}

Figure 6 illustrates results of the environmental monitoring study in the VHS vicinity in relation to operation of BTC, which are represented by the EF values for individual elements. A column graph in Figure 6 compares EF values averaged in three sets of samples: a set of RD samples collected long before BTC opening (December 2012 to September 2013), and two sets of APM samples collected shortly before BTC opening (June to July 2014) and immediately before BTC opening and during its pilot operation (February 2015 to April 2016). It identifies clearly the elements that have been significantly enriched relative to the uncontaminated environment represented by the UCC average composition.

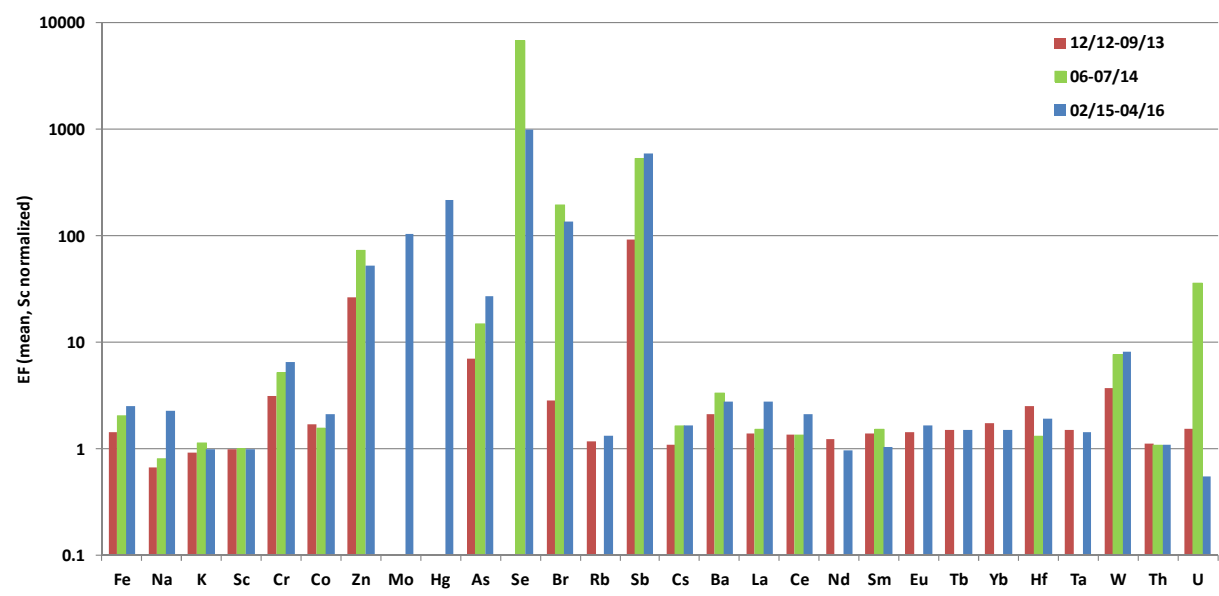

Figure 6. Enrichment factors EF (normalized to Sc and UCC) determined in samples collected in the vicinity of the $\mathrm{V}$ Holešovičkách street in Prague in relation to operation of the Blanka Tunnel Complex (BTC). Average values in a set of road dust samples collected long before BTC opening $(12 / 2012$ to $09 / 2013)$, and two sets of airborne particulate matter samples collected shortly before BTC opening (06-07/2014) and immediately before BTC opening and during its pilot operation $(02 / 2015$ to $04 / 2016)$.

The highest EF values were found for the elements $\mathrm{Se}, \mathrm{Sb}, \mathrm{Hg}, \mathrm{Br}, \mathrm{Mo}, \mathrm{Zn}$, As, W, and $\mathrm{Cr}$ (in the order of decreasing EF; up to 20,000 for Se). For U, a high EF value of 72 was observed only in the sampling period June to July 2014 (see below discussion of Figure 8). Other elements have EF values mostly only slightly higher than 1 . None of the elements in the analyzed samples seem to be significantly depleted relative to UCC. Regarding the heavy traffic as the main supposed source of anthropogenic contamination in the VHS surrounding, the high EF values can probably be associated with automotive emissions whose sources include exhaust gases, materials released from wear of brakes, camshaft, transmission and steer systems, tires, from leakage of fuel, lubricants, coolants, and discharge tube gases, etc. [18-29]. The highest EF value for Se is quite surprising because this element has not usually been reported among the main contaminants associated with traffic. High Se content in APM samples collected near VHS could be attributed to a high Se content in crude oil [30] and thus possibly also in products made from it-petrol and diesel fuels, asphalt, and tire rubber [21]. Selenium in tire production, besides its natural presence accompanying sulfur, can be added as a part of vulcanization additives [31]. Additionally, the high $E F$ values for $\mathrm{Br}$ were not expected regarding the fact that leaded petrol containing brominated compounds as additives [18,19] has generally not been available in the Czech 
Republic since 2001. In addition, Br-containing refrigerants in car air conditioning systems should not be used nowadays. Brominated flame retardants have mostly been reported from indoor environments including cars, but they have been identified also in RD [28]. Regarding the frequent presence of pollen particles observed by SEM in the samples on filters, biogenic emission sources of Se [32] and $\mathrm{Br}$ [33] should also be considered.

\subsection{Principal Component Analysis}

Further analysis of the elemental composition of RD and APM samples from the VHS vicinity was carried out using the Principal Component Analysis (PCA), a multivariate statistical technique generating from a linear combination of analyzed variable new uncorrelated variables-principal components (or factors). Results of the PCA presented in Figure 7 revealed that $64.7 \%$ of the dispersed variable (eigenvalue) could be assigned to two factors.

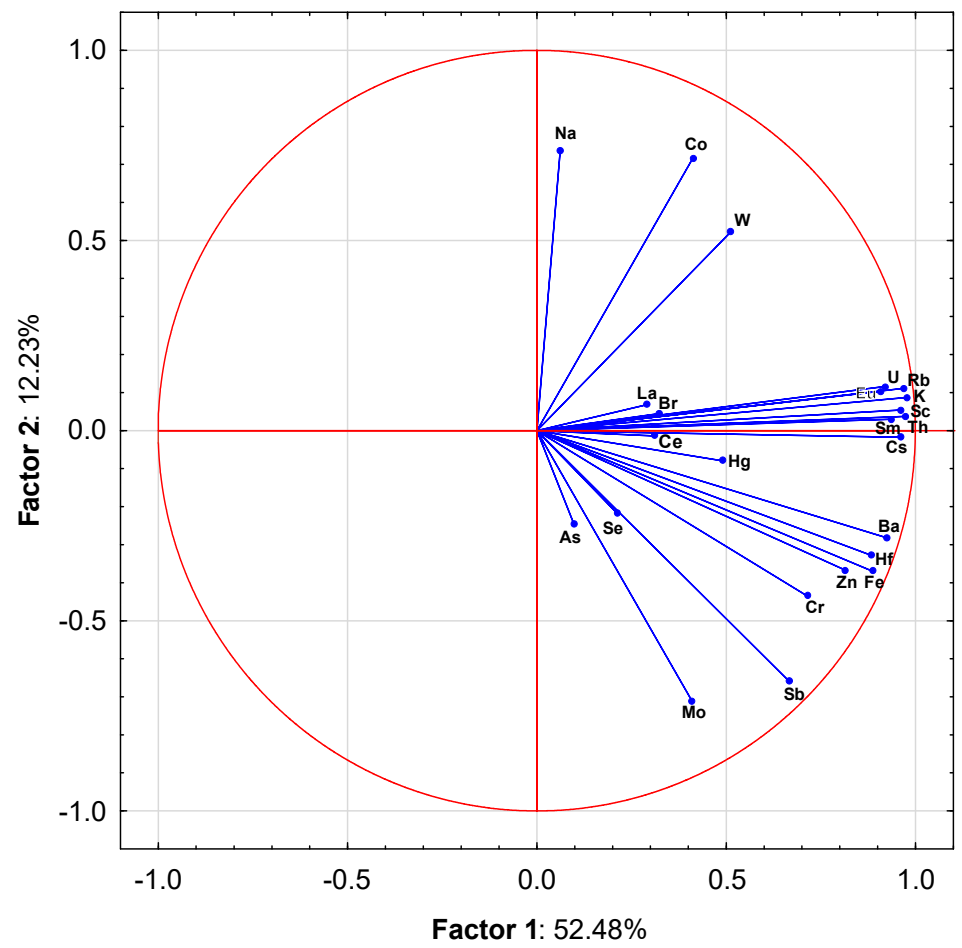

Figure 7. Results of PCA carried out on element masses determined in samples collected in the vicinity of the V Holešovičkách street in relation to operation of the Blanka Tunnel Complex in Prague.

Three to five groups of elements can be distinguished. The elements $\mathrm{K}, \mathrm{Rb}, \mathrm{Cs}, \mathrm{Sc}, \mathrm{Sm}$, $\mathrm{Eu}, \mathrm{Th}$, and $\mathrm{U}$ display high positive loadings (>0.8) in Factor 1 and very low loadings in Factor 2. These lithophile elements probably originated from the detrital material. From them, the elements $\mathrm{Ba}, \mathrm{Cr}, \mathrm{Fe}, \mathrm{Zn}$, and $\mathrm{Hf}$ with slightly lower loadings in Factor 1 and significant negative loadings in Factor 2 are somewhat separated, and approach Mo and $\mathrm{Sb}$, which have even lower loadings in Factor 1 and more negative loadings in Factor 2. Regarding the discussion of their high EF values in the previous section, the latter two groups of elements may be associated with the traffic. However, regarding also typical association of most of these elements with black shales [34], their enrichment in local detritus that originated from black shales with marginal presence of Fe ores [8] should also be considered. High (>0.5) positive loadings in Factor 2 and low loadings in Factor 1 for $\mathrm{Na}, \mathrm{Co}$, and $\mathrm{W}$ suggest a significant nondetrital proportion in their sources. These may be anthropogenic including traffic related ones, but probably with different production or transport routes than the previous two groups. Volatile elements $\mathrm{As}, \mathrm{Se}, \mathrm{Hg}$, and $\mathrm{Br}$, together with two rare earth elements, La and $\mathrm{Ce}$, displayed very low positive loadings in both factors. While the association of the volatile elements with the traffic (fuel combustion) 
was expected, the presence of La and Ce in this group (and outside the group of lithophile elements including other rare earth elements) is not clear. The low loadings may reflect higher dispersion and lower inter-element correlation in the data due to seasonality and other factors (see Figure 5 and discussion of results in the following section). To summarize, the decrease in Factor 1 loadings and increase in Factor 2 loadings (both negative and positive) may indicate a shift from the detrital to anthropogenic (probably traffic related) and possibly biogenic origin of the analyzed RD and APM samples.

\subsection{Enrichment Factor Progress}

The progress of the EF value which allows the assessment of the environmental impact of starting BTC operation, was already illustrated in Figure 6 presenting the average EF values in three monitoring seasons (long and shortly before BTC opening and during its pilot operation). Detailed information on EF values in individual sampling campaigns is presented in Figures 8 and 9. It is obvious that there is a large difference between the RD samples collected in the years 2012-2013 at the edge of VHS and the APM samples collected on filters farther from VHS. The EF values for the main traffic-related contaminants are significantly lower in RD samples, for $\mathrm{Sb}$ almost by an order of magnitude. For some elements such as $\mathrm{Se}, \mathrm{Br}, \mathrm{Mo}$, and $\mathrm{Hg}$, EF could not even be evaluated because their levels did not exceed INAA detection limits. That may be attributed to higher volatility of those elements and their preferential association with fine dust fractions and capture in aerosols, which are transported and deposited farther from the motorway [22,26]. Several elements could not be detected also in APM samples collected in 2014, possibly because a less efficient pump was used and only a quarter of each filter was available for INAA.
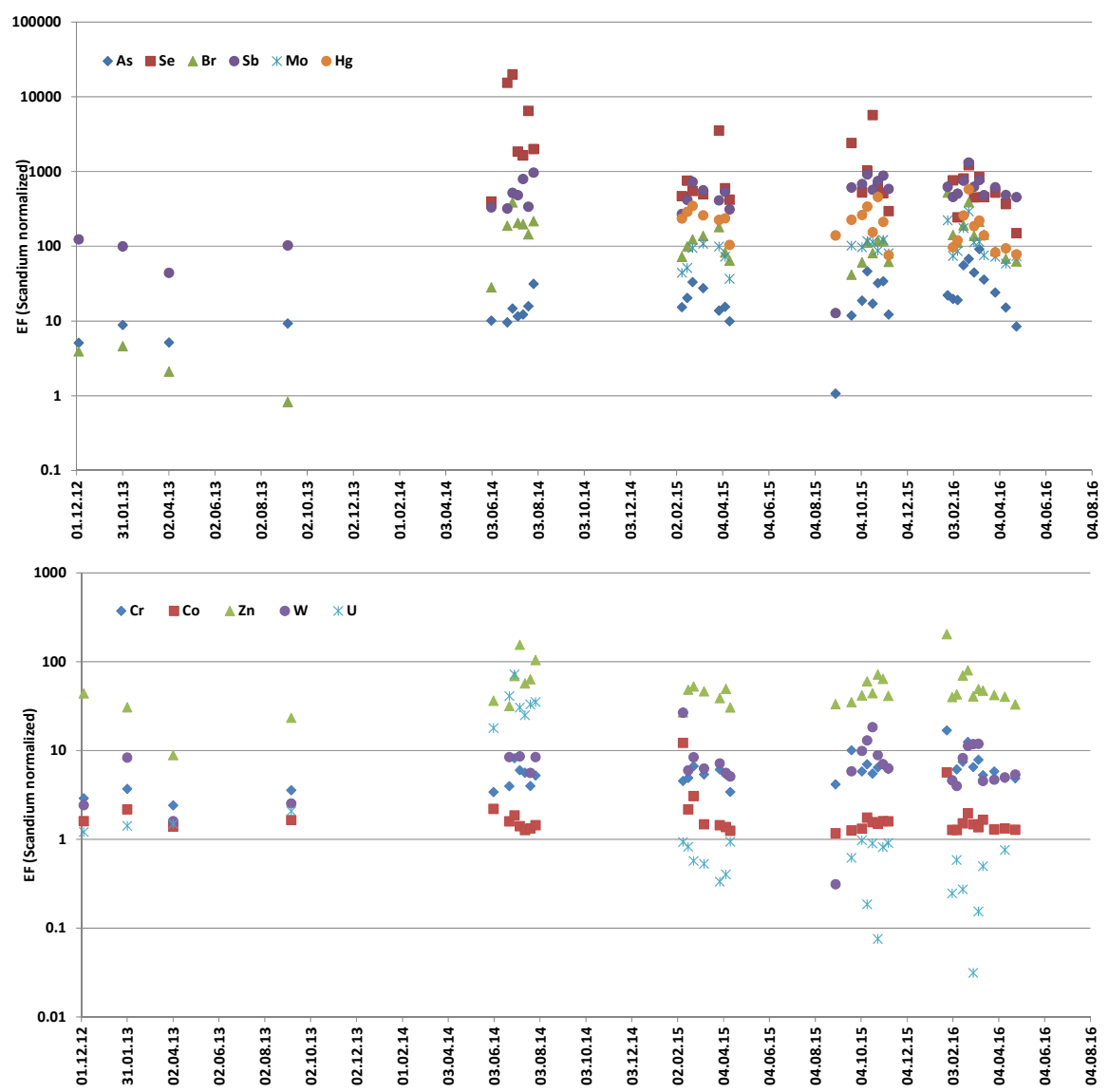

Figure 8. Progress of enrichment factors EF (normalized to Sc and UCC) determined in samples collected in the vicinity of the V Holešovičkách street in Prague in relation to opening of the Blanka Tunnel Complex in September 2015. Samples of road dust (2012-2013) and airborne particulate matter (since 2014). Elements with high to medium enrichment. 

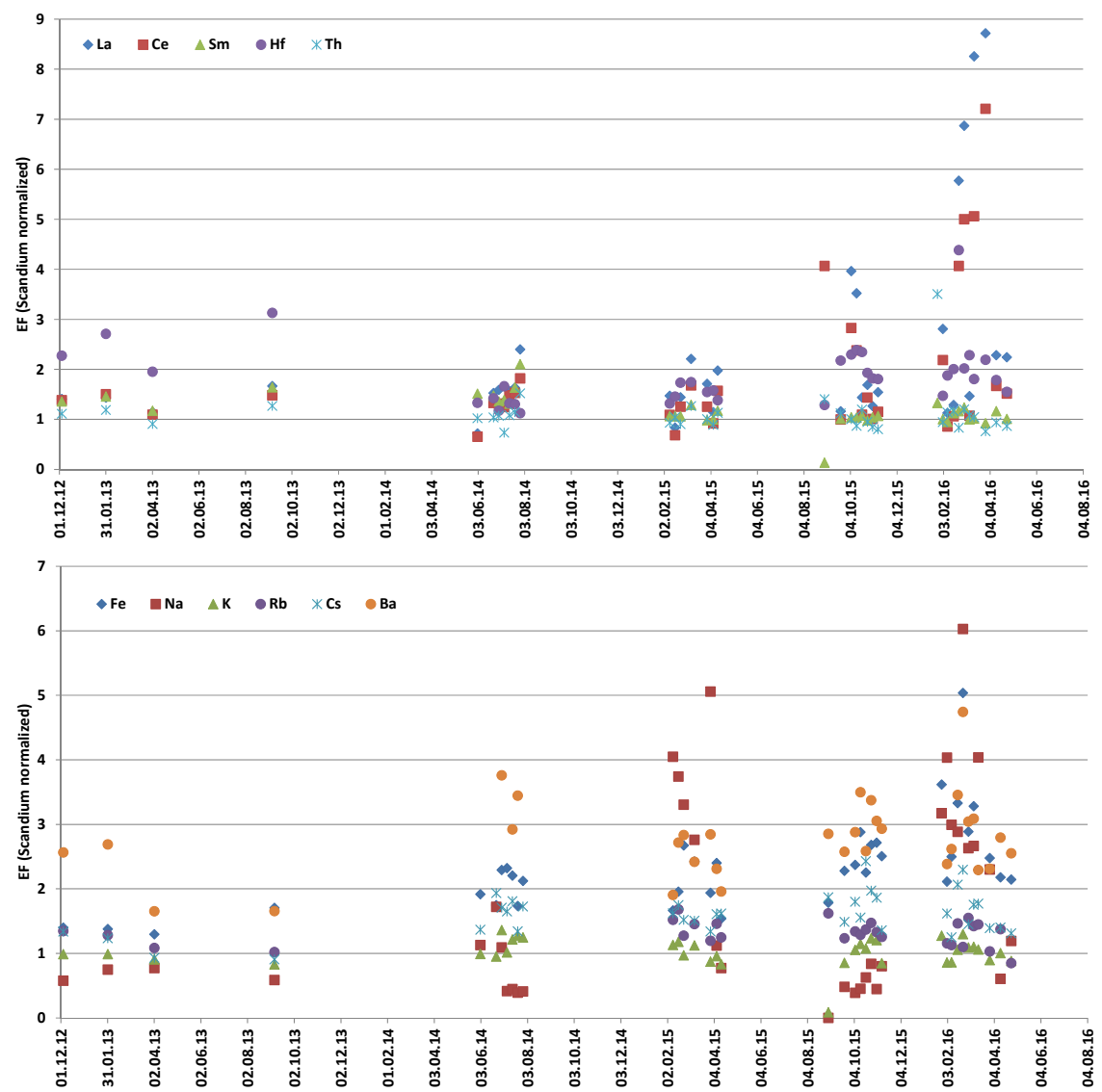

Figure 9. Progress of enrichment factors EF (normalized to Sc and UCC) determined in samples collected in the vicinity of the V Holešovičkách street in Prague in relation to opening of the Blanka Tunnel Complex in September 2015. Samples of road dust (2012-2013) and airborne particulate matter (since 2014). Elements with medium to low enrichment.

Figure 8 illustrates the progress of $E F$ values for the elements with high to medium enrichment in RD and APM samples relative to UCC. The high EF values $\left(10^{1}\right.$ to $\left.10^{4}\right)$ in these elements can probably be attributed to the heavy traffic in VHS. However, even for these elements an unambiguous trend cannot be observed in comparison of sampling periods before and after opening BTC, particularly when comparing APM samples from the periods immediately before BTC opening (February to April 2016) with the samples collected during the pilot operation of BTC (after September 2015). These samples were collected and analyzed under consistent experimental conditions (roughly identical sampling yield and analyzed sample mass). Despite a significant increase in the traffic volume in VHS (see Figures 2 and 3), the trends observed in Figure 8 are more or less constant, with relatively low fluctuations between individual samples. Among the elements with a high enrichment there is also uranium due to high EF values (18 to 72) between June and August 2014, although in other seasons $E F$ values lower than 1, sometimes significantly, were usually determined. The source of the increased uranium content is not clear, but it probably cannot be associated with traffic. An analytical artifact such as sample contamination or higher blank cannot be excluded.

In Figure 9, the progress of $E F$ values for the elements with medium to low enrichment is presented. These are mostly lithophile elements and iron as a siderophile element. For some elements, particularly $\mathrm{Na}, \mathrm{Fe}, \mathrm{La}$, and $\mathrm{Ce}$, relatively great fluctuations between sampling campaigns and even within a single short campaign can be observed. These fluctuations may be related to relatively high uncertainties (up to several tens of percent for relative uncertainties) of determination of element content in minute samples, but also to seasonal and weather conditions or other effects such as building operations in the 
IRSM complex and its surroundings (e.g., dust with increased levels of lithophile elements contained in construction materials). For La and $\mathrm{Ce}$, rarely occurring higher than corrected blank in packing polyethylene capsules cannot be excluded.

The increased EF values for $\mathrm{Fe}, \mathrm{Ba}$, and $\mathrm{Na}$ could be associated with the heavy traffic (e.g., with salting and sanding the road in winter) but they do not follow an unambiguous trend when comparing the situation before and after BTC opening.

\section{Conclusions}

Monitoring of the environmental situation near a main road connected to the Blanka Tunnel Complex (BTC) in Prague by analysis of elemental composition of road dust and airborne particulate matter showed a significant enrichment of airborne particulate matter with the elements Se, Sb, Hg, Br, Mo, Zn, As, W, Cr, Ba, and Fe. This enrichment can, with a high probability, be associated with heavy traffic, although partial origin from local detritus cannot be excluded considering dominance of black shales in the geological setting of the study area. A significant increase in contaminants associated with heavy traffic was not observed shortly after starting BTC operation in comparison with the situation before BTC opening. The study did not measure the standard parameters for particulate matter $\left(\mathrm{PM}_{10}\right.$ and $\mathrm{PM}_{2.5}$ concentrations), but compliance with the air quality standards or their exceedance for critical elements could not be judged regardless, due to their absence in the Czech and European legislation.

Great potential of INAA for multielement trace analysis of minute samples (down to $20 \mu \mathrm{g}$, with detection limits for some element down to sub-ng level) in an urban geochemistry study was demonstrated. Although INAA cannot compete with today's commonly used standardized method such as ICP-AES(OES) and ICP-MS in sensitivity and number of elements determined, it may have some advantages over them. Most importantly, it does not require sample dissolution, which often presents risk of loss of analyte or its incomplete dissolution, e.g., in some resistant minerals, and of the presence of reagent blank and other sources of contamination. Moreover, the complete destruction of sample prevents re-analysis or further analyses of the sample. In comparison with other nondestructive methods such as XRF, PIXE, and LA-ICP-MS limited to surface analysis, INAA provides benefits of bulk analysis.

Author Contributions: Conceptualization, J.M., M.H. and V.M.; methodology, J.M., M.H., V.M. and L.B.; software, D.V.; validation, J.M. and M.H.; investigation, M.H., J.M., L.B. and D.V.; resources, J.M. and M.H.; writing-original draft preparation, J.M., M.H. and D.V.; writing-review and editing, J.M.; supervision, J.M. and M.H.; project administration, M.H.; funding acquisition, J.M. and M.H. All authors have read and agreed to the published version of the manuscript.

Funding: This research was funded by the Czech Science Foundation within the project P108/12/G108, by the Ministry of Education, Youth and Sports of the Czech Republic within the projects LM2015056 (CANAM-Center of Accelerators and Nuclear Analytical Methods) and LM2015074 (Nuclear Research Reactors LVR-15 and LR-0), and by the Czech Academy of Sciences within the research program Strategy AV21: Natural Hazards.

Data Availability Statement: The data presented in the table and graphs are openly available in references stated with them or on request from the corresponding author.

Conflicts of Interest: The authors declare no conflict of interest.

\section{References}

1. Available online: https://cs.wikipedia.org/wiki/Tunelový_komplex_Blanka (accessed on 15 February 2022).

2. Available online: https://portal.cenia.cz/eiasea/download/RUlBX01aUDA5M19wb3N1ZGVrRE9DXzEucGRm/MZP092 _posudek.pdf (accessed on 18 January 2022).

3. Available online: http://www.tunelblanka.info/dopady-projektu/imise/mereni-imisi-v-holesovickach/ (accessed on 18 January 2022).

4. Available online: https:/ / eur-lex.europa.eu/legal-content/EN/TXT/PDF/?uri=CELEX:32008L0050\&from=CS (accessed on 18 January 2022). 
5. Available online: https://www.tsk-praha.cz/wps/portal/root/dopravni-inzenyrstvi/blanka/ (accessed on 18 January 2022).

6. Krzyzanowski, M.; Kuna-Dibbert, B.; Schneider, J. (Eds.) Health Effects of Transport-Related Air Pollution; WHO Regional Office for Europe: Copenhagen, Denmark, 2005. Available online: https://www.euro.who.int/_data/assets/pdf_file/0006/74715/E86650 .pdf (accessed on 23 February 2022).

7. Gardner, C.B.; Long, D.T.; Lyons, W.B. Urban Geochemistry. Appl. Geochem. 2017, 83, 1-2. [CrossRef]

8. Available online: https://mapy.geology.cz/geocr50/?center $=-738600 \% 2 \mathrm{C}-1040800 \% 2 \mathrm{C} 102067 \&$ level $=8$ (accessed on 15 February 2022).

9. Chlupáč, I. Geology of the Barrandian. A Field Trip Guide; Senckenberg Bücher, Nr. 69; Verlag Waldemar Kramer: Frankfurt am Main, Germany, 1993; 165p, ISBN 978-3-510-61276-5.

10. Vacek, F.; Žák, J. A lifetime of the Variscan orogenic plateau from uplift to collapse as recorded by the Prague Basin, Bohemian Massif. Geol. Mag. 2019, 156, 485-509. [CrossRef]

11. Žitnik, M.; Budnar, M.; Ravnikar, K.; Urši, M.; Grlj, N.; Jakomin, M.; Rupnik, Z.; Pelicon, P. Estimation of possible airborne elemental inputs to the Slovenian marine environment. J. Radioanal. Nucl. Chem. 2008, 275, 17-28. [CrossRef]

12. ̌̉anda, Z.; Frána, J.; Mizera, J.; Kučera, J.; Novák, J.K.; Ulrych, J.; Belov, A.G.; Maslov, O.D. Instrumental neutron and photon activation analysis in the geochemical study of phonolitic and trachytic rocks. Geostand. Geoanal. Res. 2007, 31, 275-283. [CrossRef]

13. Mizera, J.; Řanda, Z. Instrumental neutron and photon activation analyses of selected geochemical reference materials. J. Radioanal Nucl. Chem. 2010, 284, 157-163. [CrossRef]

14. Greenberg, R.R.; Bode, P.; De Nadai Fernandes, E.A. Neutron activation analysis: A primary method of measurement. Spectrochim. Acta Part B Atomic Spectrosc. 2011, 66, 193-241. [CrossRef]

15. Available online: https://www-nds.iaea.org/relnsd/vcharthtml/VChartHTML.html (accessed on 18 January 2022).

16. Rudnick, R.L.; Gao, S. The Composition of the Continental Crust. In Treatise on Geochemistry; Holland, H.D., Turekian, K.K., Eds.; Elsevier-Pergamon: Oxford, UK, 2003; Volume 3, pp. 1-64. [CrossRef]

17. Kłos, A.; Rajfur, M.; Wacławek, M. Application of enrichment factor (EF) to the interpretation of results from the biomonitoring studies. Ecol. Chem. Eng. S 2011, 18, 171-183.

18. Thomas, V.M.; Bedford, J.A.; Cicerone, R.J. Bromine emissions from leaded gasoline. Geophys. Res. Lett. 1997, $24,1371-1374$. [CrossRef]

19. Lammel, G.; Röhr, A.; Schreiber, H. Atmospheric lead and bromine in Germany: Post-abatement levels, variabilities and trends. Environ. Sci. Pollut. Res. 2002, 9, 397-404. [CrossRef]

20. Councell, T.B.; Duckenfield, K.U.; Landa, E.R.; Callender, E. Tire-wear particles as a source of zinc to the environment. Environ. Sci. Technol. 2004, 38, 4206-4214. [CrossRef]

21. Lönnermark, A.; Blomqvist, P. Emissions from Tyre Fires; SP Report 2005:43; SP Swedish National Testing and Research Institute: Borås, Sweden, 2005. Available online: http://www.diva-portal.org/smash/get/diva2:962334/FULLTEXT01.pdf (accessed on 18 January 2022).

22. Iijima, A.; Sato, K.; Yano, K.; Tago, H.; Kato, M.; Kimura, H.; Furuta, N. Particle size and composition distribution analysis of automotive brake abrasion dusts for the evaluation of antimony sources of airborne particulate matter. Atmos. Environ. 2007, 41, 4908-4919. [CrossRef]

23. Wen, H.; Carignan, J. Reviews on atmospheric selenium: Emissions, speciation and fate. Atmos. Environ. 2007, 41, 7151-7165. [CrossRef]

24. Won, J.H.; Park, J.Y.; Lee, T.G. Mercury emissions from automobiles using gasoline, diesel, and LPG. Atmos. Environ. 2007, 41, 7547-7552. [CrossRef]

25. McKenzie, E.R.; Money, J.E.; Green, P.G.; Young, T.M. Metals associated with stormwater-relevant brake and tire samples. Sci. Total Environ. 2009, 407, 5855-5860. [CrossRef] [PubMed]

26. Xia, L.; Gao, Y. Characterization of trace elements in PM2.5 aerosols in the vicinity of highways in northeast New Jersey in the U.S. east coast. Atmos. Pollut. Res. 2011, 2, 34-44. [CrossRef]

27. Liu, Q.; Liu, Y.; Zhang, M. Mercury and cadmium contamination in traffic soil of Beijing, China. Bull. Environ. Contam. Toxicol. 2012, 88, 154-157. [CrossRef]

28. Cao, Z.; Xu, F.; Covaci, A.; Wu, M.; Wang, H.; Yu, G.; Wang, B.; Deng, S.; Huang, J.; Wang, X. Distribution patterns of brominated, chlorinated, and phosphorus flame retardants with particle size in indoor and outdoor dust and implications for human exposure. Environ. Sci. Technol. 2014, 48, 8839-8846. [CrossRef]

29. Grigoratos, T.; Martini, G. Brake wear particle emissions: A review. Environ. Sci. Pollut. Res. 2015, 22, 2491-2504. [CrossRef]

30. Lemly, A.D. Aquatic selenium pollution is a global environmental safety issue. Ecotoxicol. Environ. Saf. 2004, 59, 44-56. [CrossRef]

31. Sánchez-Ocampo, A.; Torres-Pérez, J.; Jiménez-Reyes, M. Selenium levels in the serum of workers at a rubber tire repair shop. Am. Ind. Hyg. Assoc. J. 2010, 57, 72-75. [CrossRef]

32. Quinn, C.F.; Prins, C.N.; Freeman, J.L.; Gross, A.M.; Hantzis, L.J.; Reynolds, R.J.; Yang, S.I.; Covey, P.A.; Bañuelos, G.S.; Pickering, I.J.; et al. Selenium accumulation in flowers and its effects on pollination. New Phytol. 2011, 192, 727-737. [CrossRef] [PubMed]

33. Gan, J.; Yates, S.R. Production of methyl bromide by terrestrial higher plants. Geophys. Res. Lett. 1998, 25, 3595-3598. [CrossRef]

34. Parviainen, A.; Loukola-Ruskeeniemi, K. Environmental impact of mineralised black shales. Earth-Sci. Rev. 2019, 192, 65-90. [CrossRef] 